\title{
Video-Assisted Thoracic Surgery for Late Recurrence of Congenital Diaphragmatic Hernia
}

\author{
Walther Brochier ${ }^{1,2, *}$, Maryam Monfared Rezai ${ }^{3}$ and Julien Mahieu ${ }^{1}$ \\ 1 Department of Abdominal, Endocrine and Thoracic Surgery, Clinique Saint-Jean, 1000 Brussels, Belgium; \\ jmahieu@clstjean.be \\ 2 Institut de Duve, Université Catholique de Louvain, 1200 Brussels, Belgium \\ 3 Department of Radiology, Clinique Saint-Jean, 1000 Brussels, Belgium; mrezai@clstjean.be \\ * Correspondence: walther.brochier@uclouvain.be
}

check for

updates

Citation: Brochier, W.; Rezai, M.M.;

Mahieu, J. Video-Assisted Thoracic

Surgery for Late Recurrence of

Congenital Diaphragmatic Hernia.

Surgeries 2021, 2, 144-149. https://

doi.org/10.3390/surgeries2020014

Academic Editors: Cornelis Sier and Michael S. Firstenberg

Received: 9 March 2021

Accepted: 7 April 2021

Published: 10 April 2021

Publisher's Note: MDPI stays neutral with regard to jurisdictional claims in published maps and institutional affiliations.

Copyright: (c) 2021 by the authors. Licensee MDPI, Basel, Switzerland. This article is an open access article distributed under the terms and conditions of the Creative Commons Attribution (CC BY) license (https:// creativecommons.org/licenses/by/ $4.0 /)$.

\begin{abstract}
Congenital diaphragmatic hernia ( $\mathrm{CDH})$ is often diagnosed and treated in the perinatal period. Recurrence is a known complication that may very rarely occur years after the operation. We report here the case of a patient who had an operation for a $\mathrm{CDH}$ at birth that then recurred in adulthood. Given the risk of complications and the symptomatology of the patient, we decided to treat the patient surgically. We successfully performed a video-assisted thoracic surgery (VATS) procedure during which we reduced the hernia and closed the breach. Given the recurrent nature of the hernia, we decided to reinforce the repair with a mesh.
\end{abstract}

Keywords: thoracic surgery; VATS; diaphragm; congenital hernia

\section{Introduction}

Congenital diaphragmatic hernia $(\mathrm{CDH})$ is a rare but severe disease, occurring in approximatively 1:2500 to 1:5000 newborn children [1]. A diaphragmatic hernia is very rarely diagnosed in adults. In most cases, the etiology is a CDH that became symptomatic in adulthood sometimes triggered by pregnancy [2], or an asymptomatic CDH diagnosed incidentally as a radiographic finding. Other etiologies include a trauma-induced diaphragmatic hernia. Here, however, we describe a recurrence at adulthood of a CDH repaired in infancy, a case for which the literature is very scarce.

\section{Case Description}

A 25-year-old male presented to the outpatient clinic complaining of dyspnea on exertion and left chest discomfort.

This patient has a history of left congenital diaphragmatic hernia, which was diagnosed prenatally and for which he underwent surgery on his first day of life. The hernia involved the colon, the spleen, the left lobe of the liver and part of the small intestine. Via left subcostal laparotomy, the content was reduced into the abdominal cavity and the diaphragmatic defect was closed with a direct suture. He did not suffer from pulmonary hypoplasia. The postoperative course was uneventful.

He was readmitted two and a half months later in critical condition, due to intestinal obstruction from adhesions at the site of the first surgery. He underwent a midline laparotomy, during which a necrotic intestinal loop had to be resected.

At 8 years of age, he presented with a second episode of intestinal obstruction. He underwent a second midline laparotomy for surgical adhesiolysis. There was no sign of bowel necrosis or recurrence of the diaphragmatic hernia.

In 2009, he underwent elective surgery to correct the unaesthetic median abdominal scar.

In 2010, a CT was performed as part of the follow-up of the surgery performed in 2009, in order to evaluate the integrity of the abdominal wall. The patient was asymptomatic, but a CT demonstrated a left posterolateral $3 \mathrm{~cm}$ diaphragmatic orifice. 
Between 2010 and 2018, the patient experienced increasing dyspnea on exertion and left chest discomfort. In February 2018, a CT showed the persistence of the hernia, which was measured as a $3.3 \mathrm{~cm}$ diaphragmatic orifice containing colon and greater omentum, for a total volume estimated at $560 \mathrm{cc}$ (Figures 1 and 2). He underwent preoperative consultation in June 2018, at which he complained of dyspnea, left chest discomfort, as well as occasional constipation. On clinical examination, the patient had scars from left subcostal and midline laparotomy incisions, as well as decreased left basilar breath sounds on chest auscultation.

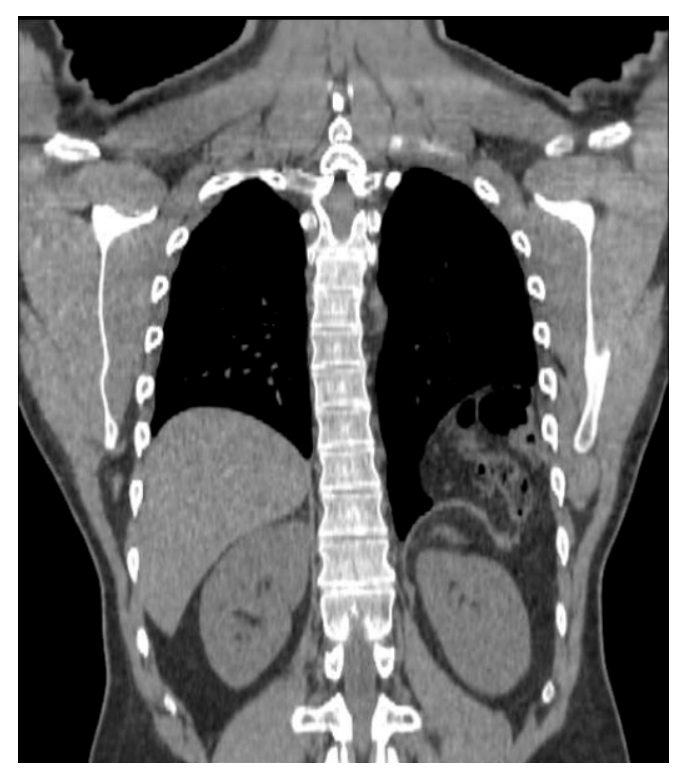

Figure 1. CT scan (performed in 2018) showing the recurrent left posterolateral hernia.

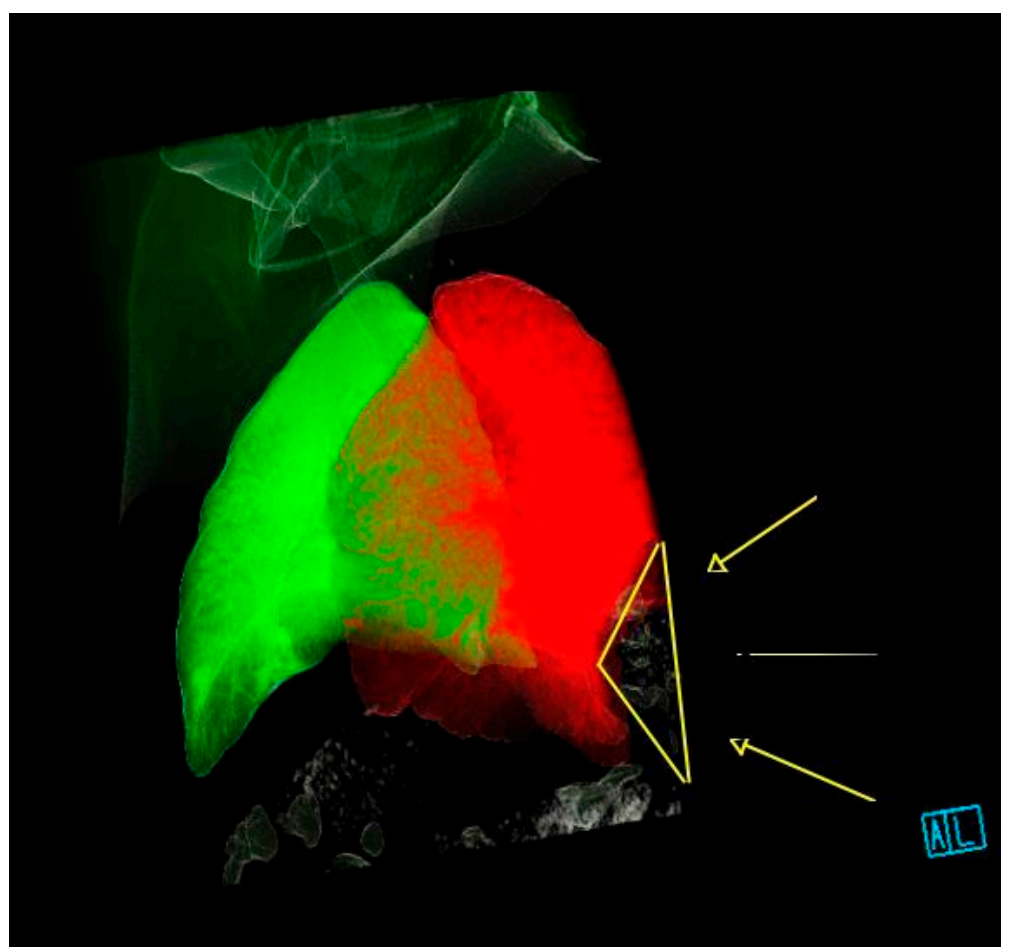

Figure 2. 3-D reconstruction of the CT-scan performed in 2018 showing the location of the hernia (yellow arrows). 
We decided to surgically repair the diaphragmatic defect to treat the patient's symptoms, as well as to decrease the risk of additional intestinal obstruction. This surgical approach was recommended by the literature [2,3].

We performed a VATS procedure. The patient was placed in the right lateral decubitus position. A $5 \mathrm{~mm}$ 30-degree thoracoscope was introduced through a $5 \mathrm{~mm}$ trocar placed in the 4th intercostal space on the anterior axillary line. After exploration of the pleural cavity and identification of the hernia, two $10 \mathrm{~mm}$ trocars were placed in the 7th intercostal space on the mid-and posterior axillary line, respectively. Two additional $5 \mathrm{~mm}$ pleurotomies were performed in the 9th intercostal space on the posterior axillary line, and in the 6th intercostal space on the anterior axillary line. After reduction of the hernia, the defect was measured as $3.5 \mathrm{~cm}$ in diameter (Figure 3). The hernia consisted of left transverse colon that was contained in a hernial sac. It was dissected and reintegrated in the abdominal cavity. Next, the defect was closed with simple interrupted stitches of a nonabsorbable, braided suture (Ethibond 0) (Figure 4). The suture line was reinforced with a $12 \mathrm{~cm}$ diameter polyvinylidene fluoride (PVDF) mesh (DynaMesh ${ }^{\circledR}$-IPOM) that was anchored with four stitches of nonabsorbable polypropylene sutures (Prolene 2-0) and surgical glue $\left(\right.$ IFABOND $\left.{ }^{\circledR}\right)$ (Figure 5). We placed one chest tube (28 Fr.) with suction $(-20 \mathrm{cmH} 20)$ at the end of the procedure. There were no intraoperative complications. Operative time was $170 \mathrm{~min}$.

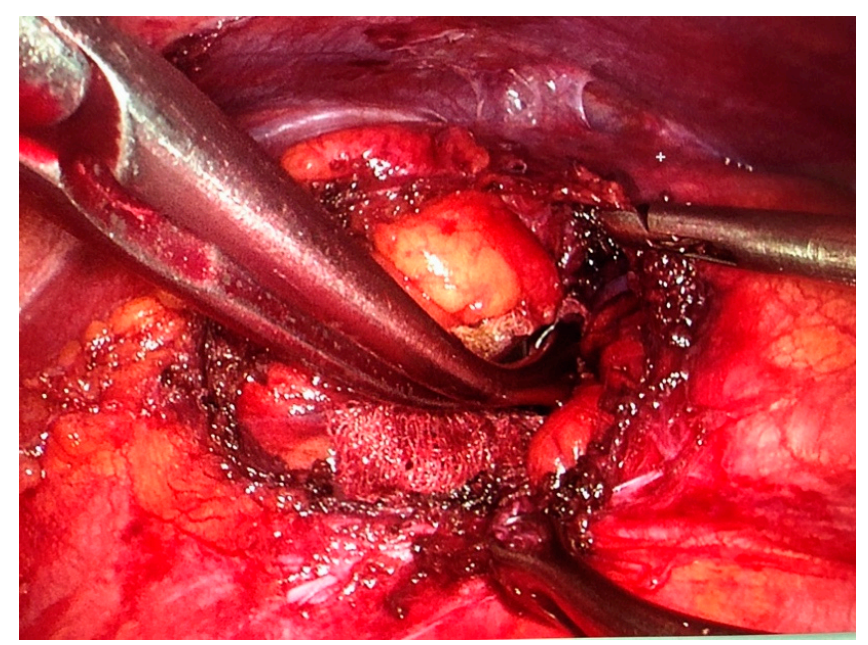

Figure 3. Diaphragmatic breach, with hernial sac dissected and pushed back in the abdominal cavity.

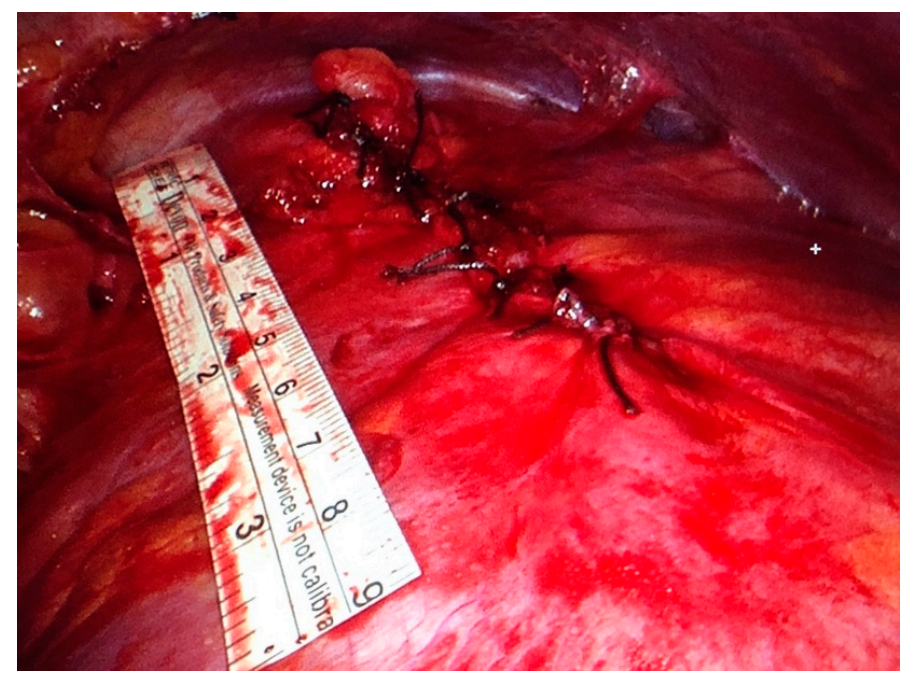

Figure 4. Herniorrhaphy of the diaphragm before the application of the mesh. 


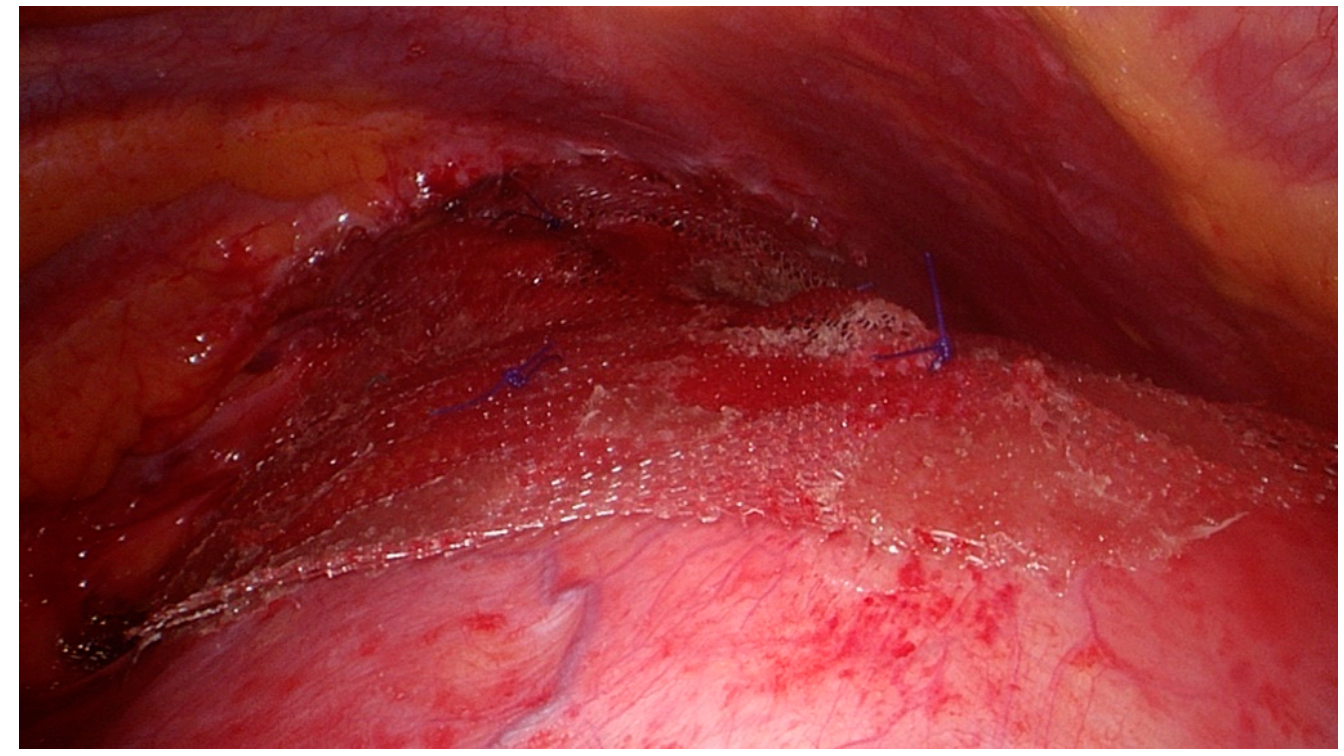

Figure 5. Application of the polyvinylidene fluoride (PVDF) mesh (DynaMesh ${ }^{\circledR}$-IPOM) anchored with four Prolene 2-0 stitches and surgical glue (IFABOND $\left.{ }^{\circledR}\right)$.

The postoperative course was uneventful. The chest tube was removed at day 3 and the patient was discharged at day 5. The patient described an improvement of his symptoms, with resolution of the dyspnea on exertion and chest discomfort. He reported slight postoperative pain on the posterior trocar access, which resolved after 6 months. At 2-year follow-up, there is no radiological sign of recurrence. Given his numerous preexisting laparotomy scars, the patient was also very satisfied with the aesthetic result (Figures 6 and 7).

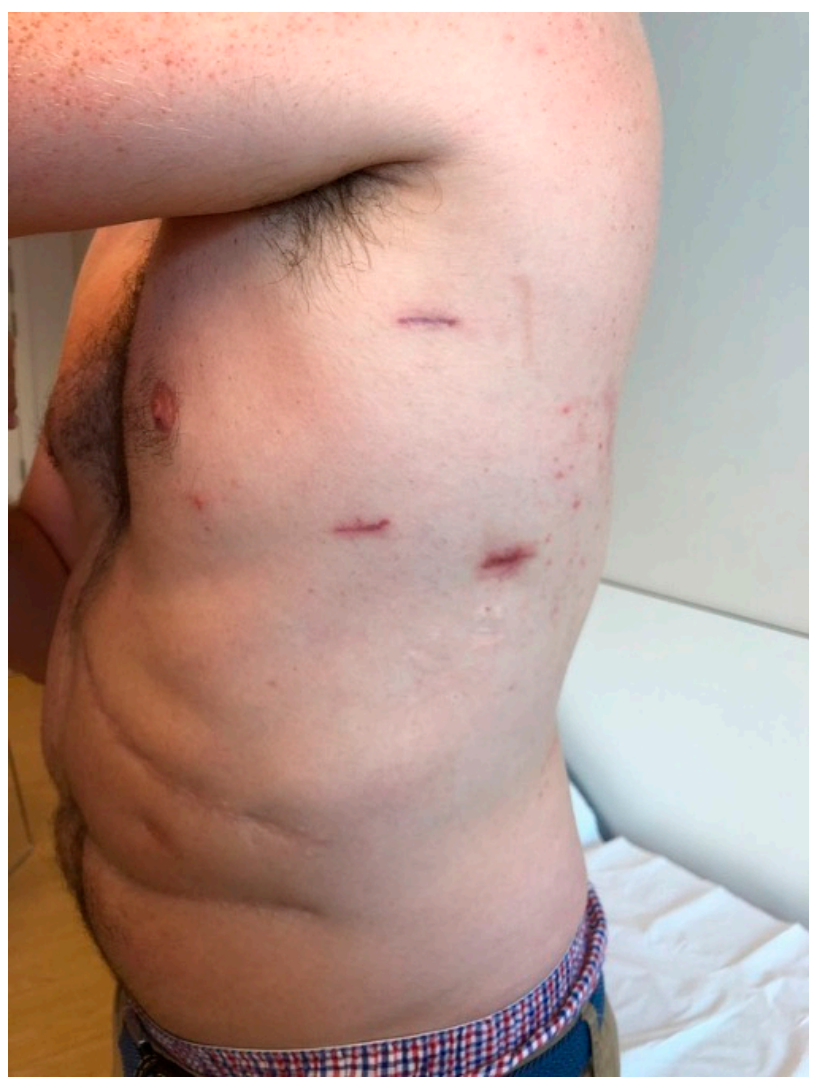

Figure 6. Anterior trocar access scars. 


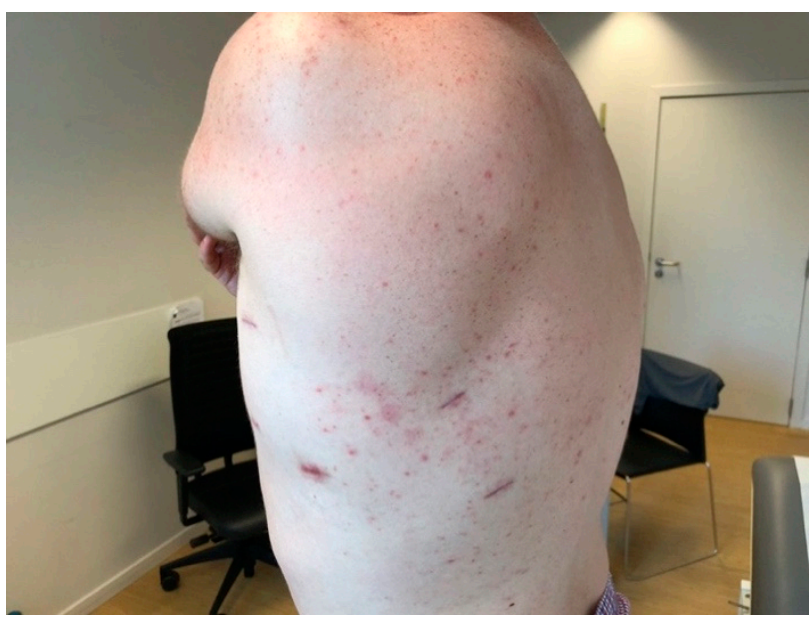

Figure 7. Posterior trocar access scars.

\section{Discussion}

Risk of recurrence after repair of $\mathrm{CDH}$ at birth is greatest during the first year of life and becomes very low after childhood. In one cohort of 187 patients described by Tim Jancelewitz et al., recurrence occurred in $23(15 \%)$, of which $70 \%$ occurred before 2 years and all before 9 years [4].

Because of the rarity of recurrence in adults, diagnosis is difficult. Symptoms of diaphragmatic hernia are not very specific and include abdominal symptoms such as abdominal pain, nausea and vomiting, and thoracic symptoms, such as shortness of breath and chest discomfort.

The approach (abdominal vs. thoracic, minimally invasive vs. open) used for recurrent $\mathrm{CDH}$ repairs in adults should, in our opinion, be selected based on the surgeon's experience and the patient's history. In our case, the thoracic approach was ideal given his history of multiple abdominal surgeries.

In the setting of an elective repair, a minimally invasive approach should, in our opinion, be considered when appropriate. There exists now in the literature a few cases, including ours, that demonstrate that a minimal access by VATS [5-7] or RATS [8] is feasible. This case demonstrates that a significant hernia volume is not an absolute contraindication to a VATS approach.

We did not find any literature addressing use of a mesh reinforcement in repair of late recurrent diaphragmatic hernia. In this case, we chose to use mesh to minimize the risk of recurrence in the very long term. Not only was the hernia of a recurrent nature, but this young, healthy, and active patient also has a long-life expectancy. We opted for a biface mesh made of polypropylene (PP) on one side and polyvinylidene fluoride (PVDF) on the other (DynaMesh ${ }^{\circledR}$-IPOM). The PP side was placed on the diaphragmatic side, as it would be placed on the parietal side in case of a laparoscopically treated incisional hernia. We opted for this patch because we were able to fully close the diaphragmatic defect. Had this not been possible, we would not have used this mesh, because the PP side would have been in contact with the peritoneal cavity and would have created adhesions. We then would have used a PTFE patch $\left(G_{\text {GORE }}{ }^{\circledR}\right.$ DualMesh $\left.{ }^{\circledR}\right)$, where the smooth side would be placed in contact with the abdominal cavity.

In conclusion, recurrence in adults of a diaphragmatic hernia operated at birth-that might be called "transdiaphragmatic eventration" — is a very rare event. When diagnosed, it should be followed-up and surgically treated because of the risk of intestinal strangulation.

A minimally invasive procedure can be carried out, even when the hernia volume is large, and must be considered because it reduces length of hospitalization and cost, decreases patient morbidity, and increases patient comfort. 
The use of a mesh in the case of late recurrent diaphragmatic hernias, even when tension-free closure is achieved is, as per our experience, recommended to reinforce the repair and to prevent further recurrence, particularly in young and healthy adults.

Author Contributions: Writing—original draft preparation, W.B.; writing—review and editing, W.B. and J.M.; resources (CT scan images), M.M.R.; supervision, J.M. All authors have read and agreed to the published version of the manuscript.

Funding: This research received no external funding.

Institutional Review Board Statement: Our manuscript does not really involve research on a patient, since it is a case report. In this context, we did not need approval of an ethics committee.

Informed Consent Statement: Written informed consent has been obtained from the patient to publish this paper.

Data Availability Statement: No new data were created or analyzed in this study. Data sharing is not applicable to this article.

Acknowledgments: The authors wish to thank Auriane Sibille, Stephen Judge and Menal Jham for editorial assistance.

Conflicts of Interest: The authors declare no conflict of interest.

\section{References}

1. Clifton, M.S.; Wulkan, M.L. Congenital Diaphragmatic Hernia and Diaphragmatic Eventration. Clin. Perinatol. 2017, 44, 773-779. [CrossRef] [PubMed]

2. $\quad$ Matsudera, S.; Nakajima, M.; Takahashi, M.; Muroi, H.; Kikuchi, M.; Shida, Y.; Thara, K.; Yamaguchi, S.; Sasaki, K.; Tsuchioka, T.; et al. Laparoscopic surgery for a Bochdalek hernia triggered by pregnancy in an adult woman: A case report. Int. J. Surg. Case Rep. 2018, 48, 10-15. [CrossRef] [PubMed]

3. Schumacher, L.; Gilbert, S. Congenital Diaphragmatic Hernia in the Adult. Thorac. Surg. Clin. 2009, 19, 469-472. [CrossRef] [PubMed]

4. Jancelewicz, T.; Chiang, M.; Oliveira, C.; Chiu, P.P. Late surgical outcomes among congenital diaphragmatic hernia (CDH) patients: Why long-term follow-up with surgeons is recommended. J. Pediatr. Surg. 2013, 48, 935-941. [CrossRef] [PubMed]

5. Shen, Y.-G.; Jiao, N.-N.; Xiong, W.; Tang, Q.; Cai, Q.-Y.; Xu, G.; Liang, G.-Y. Video-assisted thoracoscopic surgery for adult Bochdalek hernia: A case report. J. Cardiothorac. Surg. 2016, 11, 165. [CrossRef] [PubMed]

6. Amer, K. Thoracoscopic approach to congenital diaphragmatic hernias in adults: Southampton approach and review of the literature. J. Vis. Surg. 2017, 3, 176. [CrossRef] [PubMed]

7. Gwan-Nulla, D. VATS Repair of Recurrent Congenital Bochdalek Hernia with Intrathoracic Herniation of the Kidney and Portion of the Pancreas. 2017. Available online: https:/ / www.ctsnet.org/article/vats-repair-recurrent-congenital-bochdalek-herniaintrathoracic-herniation-kidney-and (accessed on 12 April 2019).

8. Lima, M.; Di Salvo, N.; Ugolini, S.; Libri, M.; Ruggeri, G. Robot-assisted thoracoscopic repair of a late-onset Bochdalek hernia: A case report. Pediatr. Med. Chir. 2018, 40, 23-26. [CrossRef] [PubMed] 